details of operative techniques. Readers must not expect the standard of photography available in books on operative surgery. The book will be of some interest to those who have been influenced by the author's work.

C. M. RIDLEY,

Whittington Hospital, London N19 5NF

\section{Obstetric and Perinatal Immunology (No 16 in Current Topics in Immunology Series, edited by John Turk)}

By Maurice N. Cauchi. Pp. ix +148 , illustrated. Edward Arnold. London. $£ 12.50$.

Doctor M.N. Cauchi sets out to discuss obstetric and perinatal immunology in 6 chapters: (1) Immunological aspects of the maternal-fetal interaction; (2) Immunological aspects of normal pregnancy; (3) Immune responses in the fetus and neonate; (4) Preeclamptic and other pregnancy-associated conditions; (5) Autoimmune disease in pregnancy; and (6) Prospects and perspectives. In the first chapter, there are numerous references to studies in laboratory animals which have questionable relevance to humans. The reader is told that it is 'unlikely that the secretory immunoglobulins in the uterus have any role to play in the maintenance of the fertilized ovum', but justification of this statement is not forthcoming. The section on blood group antigens is good, but comments on spontaneous abortion are not contemporary. Chapter 2 on immunological aspects of normal pregnancy is uncritical and leaves practically everything that has ever been measured as being of possible importance. This may be broadly true, but obstetricians need some horses onto which to place their bets. Chapter 3 contains some useful tables and figures, but one wonders about the validity of referring to T-cells in 1960 publications, before T-cells were described! Comments on the third component of complement in 1969 could also be usefully updated, as could 'unpublished observations' by the author concerning IgD on fetal lymphocytes, especially when so many good papers on this subject have been published. Chapter 4 on pre-eclampsia and other pregnancyassociated conditions, which is a rapidly advancing aspect of pregnancy research, provides too many old references. Immunogenetics is not seriously considered, and the role of HLA on trophoblast is largely misrepresented. Chapter 5 on autoimmune diseases in pregnancy wisely refers to Scott, for otherwise readers are told that systemic lupus erythematosus is a chronic multisystem inflammatory disease of 'females', which is only half time. The photomicrographs in this chapter are appalling, which is not the author's fault. The final chapter talks about 'sperm agglutinating antibody... in ... patients following vasectomy' and ' $\mathrm{IgE}$ as an immunoregulatory agent in pregnancy', both topics requiring more than honorable mention. I am not impressed by this book, but it is at least a step in the right direction. to close the present gap in hiatus betweeg research in obstetrics and the application of this knowledge te current practice.

W. Page Faulk.

Faculté de Médecine,

Université de Nice,

06034 Nice, Fránce.

\section{Scientific Foundations of Paediatrics}

Edited by John A. Davis and John Dobbing. 2nd edn. Ppũ xvi +1095 , illustrated. William Heinemann Medical Books, London. 1981. £75.00.

This is not a text book of paediatrics but rather a compendium of essays on human developmental biology. It is the second edition of $\Phi$ book first published in 1974 and has now attained monumentad proportions. There is an array of 70 distinguished contributors from 12 countries whose labours have resulted in over a thousand pages of text. The concept reflects the editors' belief that the study of development in its widest context is the foundation on which moderb paediatrics must rest. The majority of the chapters are concerne $\infty$ with the growth and development of individual systems and organs with the emphasis ranging from anatomical structure to biochemicat function. A new and welcome addition is devoted to the growth and development of behaviour and personality.

Seven chapters are given to so-called 'climacterics' which comprise the cardio-vascular events at birth, sexual differentiation in the fetus and new-born, and puberty. Finally a group of special topiç include the epidemiological aspects of paediatrics in early life circadian rhythms, oncology, bacterial infection of the fetus and colonization of the new born, and developmental pharmacologg $\vec{\omega}$

The chapters are well written, extensively referenced, ofndo illustrated by numerous tables and graphs. The book is produced and handsomely bound. It succeeds in bringing togethềr mass of information pertinent to paediatrics which is not easis accessible elsewhere and which cannot be included in standars clinical works. Critics of major multi-author text books have argue $\bar{\Phi}$ increasingly that they impose undue constraints on authors ang्छ editors alike with the implication that a series of similar mor specialized books or monographs would be preferred. They win however find little to support that contention in this volume which is commended to hospital and departmental librarians as an invaluable source of reference which should be accessible to all doctors and students involved in paediatrics.

D. BARLTROP,

Westminster Children's Hospital, London SWIP 2NS. 